\title{
INFLUÊNCIA DO MEIO DE CULTURA, TIPO E CONCENTRAÇÃO DE CITOCININAS NA MULTIPLICAÇÃO IN VITRO DE AMOREIRA-PRETA E FRAMBOESEIRA
}

\author{
The influence of culture medium, cytokinin type and concentrations \\ on in vitro multiplication of blackberry and raspberry
}

\author{
Luciene Nolasco Leitzke', Claudia Roberta Damiani², Márcia Wulff Schuch ${ }^{1}$
}

\begin{abstract}
RESUMO
A amoreira-preta e a framboeseira são espécies pouco cultivadas no Brasil, porém representam uma ótima opção de diversificação para pequenas propriedades, por serem rústicas e com elevada produtividade. A propagação dessas espécies dá-se, principalmente, por meio de estacas de raiz e mesmo de hastes novas, porém, já é crescente o interesse pelo uso da micropropagação como um método alternativo de propagação vegetativa de plantas frutíferas. No entanto, existe a necessidade de se ajustar, para cada espécie, e/ou cultivar, as melhores condições de cultivo, para que se obtenha sucesso no processo. Assim, neste trabalho objetivou-se determinar o melhor meio de cultura (MS e WPM), o efeito das citocininas (BAP, 2iP, Zeatina) e suas concentrações $(0 ; 7,5 ; 15$ e 22,5 $\mu \mathrm{M})$ na multiplicação in vitro de amoreira-preta 'Xavante' e de framboeseira 'Batum' e 'Heritage'. De acordo com os resultados obtidos, conclui-se que, o meio MS e a citocinina BAP na concentração de $15 \mu \mathrm{M}$ foi mais eficiente para ambas as espécies e cultivares, induzindo maior número médio de folhas, brotações e gemas. Quanto ao comprimento das brotações, observou-se um comportamento diferenciado entre espécie, cultivar e regulador. Para amoreira-preta, o cultivo em meio MS na ausência de regulador promoveu o aumento do comprimento das brotações, enquanto que para framboeseira 'Batum' e 'Heritage', melhores resultados foram obtidos na presença de citocininas, respectivamente, Zeatina e 2iP, independentemente das concentrações utilizadas.
\end{abstract}

Termos para indexação: Rubus idaeus, Rubus sp., cultura de tecidos, micropropagação, pequenas frutas.

\begin{abstract}
The blackberry and raspberry are species little cultivated in Brazil. However, they represent a valuable diversification option for small farms, once they are rustic and very productive. Root cuttings and softwood stem are the most widely practiced type of propagation. Recently, there has been an increased interest in the use of micropropagation as an alternative technique for fruit plant propagation. Nevertheless, there is a need to adjust the appropriate cultivation condition for each species and/or cultivar for the process to succeed. Therefore, this research aimed at determining the most suitable culture medium (MS and WPM), the effect of cytokinines (BAP, 2iP, Zea) and their concentrations $(0 ; 7,5 ; 15$ e 22,5 $\mu \mathrm{M})$ on in vitro multiplication of blackberry cultivar Xavante and raspberry cultivar Batum and Heritage. The results have shown that the medium MS and the cytokinin BAP at $13 \mu \mathrm{M}$ for the blackberry 'Xavante' and $12 \mu \mathrm{M}$ for raspberry 'Batum' and 'Heritage' were more efficient, increasing average leaf number, shoots and buds. For the blackberry, cultivation in MS medium in the absence of regulator promoted an increase in shoot length, whereas for 'Batum' and 'Heritage' raspberries, better results were obtained in the presence of citocinines - zeatin for Batum and 2iP for Heritage, independently of the concentrations.
\end{abstract}

Index terms: Rubus idaeus, Rubus sp., tissue culture, micropropagation, small fruits.

\section{(Recebido em 29 de agosto de 2007 e aprovado em 5 de agosto de 2008)}

\section{INTRODUÇÃO}

Muitas espécies do gênero Rubus, ao qual pertencem a framboeseira e a amoreira-preta, são originárias da região mediterrânea, têm uma longa história de cultivo e hoje encontram-se disseminadas pelo mundo (Antunes, 1999).

Os maiores produtores de amoreira-preta na América do Sul são a Argentina e o Chile (Jennings \& McNicol, 1991). O Brasil, apesar de seu grande potencial, não apresenta produção significativa dessa fruta. Os estados que se destacam na produção de amoreira-preta e de framboeseira são: Rio Grande do Sul, Santa Catarina, Paraná, São Paulo e Sul de Minas Gerais, restringindo-se neste Estado, ao plantio na EPAMIG/Fazenda Experimental de Caldas.

A propagação da amoreira-preta e da framboeseira é feita, normalmente, por estacas de raízes que, por ocasião do repouso vegetativo, são preparadas e enviveiradas em sacolas plásticas. Podem também ser usados brotos

${ }^{1}$ Faculdade de Agronomia Eliseu Maciel/FAEM - Universidade Federal de Pelotas/UFPel - Departamento de Fitotecnia - Pelotas, RS ${ }^{2}$ Faculdade de Ciências Biológicas e Ambientais/FCBA, Universidade Federal da Grande Dourados/UFGD - Rodovia Dourados, Itahum, Km 12 - Cx. P. 322 - 79804-970 - Dourados, MS - claudiadamiani@ufgd.edu.br 
(rebentos) originados de plantas cultivadas, além de estacas herbáceas (Raseira et al., 1984; Antunes, 1999). Outra alternativa viável é a cultura de tecidos, por meio da micropropagação, com o intuito de se obterem plantas livres de vírus, geneticamente uniformes e em curto espaço de tempo (Santos \& Raseira, 1988). Entretanto, a elevada variabilidade de comportamento in vitro obriga a se desenvolver condições específicas de cultivo, pois nem todas as espécies do gênero Rubus possuem grande coeficiente de propagação in vitro (Leontiev-Orlov, 1989). Dentre os fatores que podem influenciar a micropropagação in vitro, podemos citar os fatores externos como temperatura, umidade relativa, fotoperíodo, intensidade luminosa e fatores intrínsecos ao crescimento e desenvolvimento vegetativo dependentes das condições nutricionais do meio de cultivo e a aplicação de fitorreguladores. A micropropagação tem como objetivo principal produzir o maior número de plantas, no menor espaço de tempo (Schuch \& Erig, 2005). A definição do meio de cultura adequado a cada espécie, o regulador e a sua concentração são imprescindíveis para o sucesso da propagação de culturas in vitro. Nesse sentido, algumas vias de estudos envolvem a reformulação dos meios nutritivos, tais como MS (Murashige \& Skoog, 1962) e WPM (Lloyd \& Mccown, 1980) e segundo Grattapaglia \& Machado (1998), a escolha do tipo de citocinina e sua concentração são fatores que influenciam no sucesso da multiplicação in vitro, e indispensáveis durante o processo de superação da dominância apical, indução proliferação de gemas axilares. Desse modo, ocorre um grande número de brotações por meio do crescimento de meristemas laterais (Sriskandarajah et al., 1982). Uma das citocininas mais utilizadas, seguida pela cinetina e isopenteniladenina (2iP) é a 6-benzilaminopurina (BAP) a qual tem se revelado eficiente no processo de multiplicação, tanto de estruturas aéreas, como na indução de gemas adventícias em diversas espécies (Hu \& Wang, 1983).

Baseado nos aspectos acima citados, neste trabalho objetivou-se avaliar o melhor meio de cultura, o efeito das citocininas e suas concentrações na multiplicação in vitro de amoreira-preta 'Xavante' e de framboeseira 'Batum' e 'Heritage'.

\section{MATERIAL E MÉTODOS}

O trabalho, realizado no Laboratório de Micropropagação de Plantas Frutíferas, do Departamento de Fitotecnia da Faculdade de Agronomia Eliseu Maciel (FAEM), da Universidade Federal de Pelotas (UFPel), em Pelotas, RS, constituiu-se de três experimentos de multiplicação in vitro, sendo o primeiro com amoreira-preta (Rubus sp. cultivar Xavante) e o segundo e terceiro experimento com framboeseira (Rubus idaeus L. cultivares Batum e Heritage).
Para a realização do experimento foram utilizados segmentos nodais caulinares, na posição vertical, de micropropágulos com aproximadamente $1 \mathrm{~cm}$ de comprimento e duas gemas axilares. Os fatores estudados foram o tipo de meio de cultura: MS (Murashige \& Skoog, 1962) e WPM (Lloyd \& Mccown, 1980), o tipo de citocinina: Zeatina, isopenteniladenina (2iP) e 6-benzilaminopurina (BAP) em quatro diferentes concentrações destes no meio de cultura $(0 ; 7,5 ; 15$ e 22,5 $\mu \mathrm{M})$. O delineamento estatístico utilizado foi o inteiramente casualizado em esquema fatorial 2X3X4, totalizando 24 tratamentos com quatro repetições. Cada repetição foi constituída de um frasco com cinco explantes.

Utilizou-se para o meio MS e WPM, 30 g.L $\mathrm{L}^{-1}$ de sacarose, 100 mg.L $L^{-1}$ de mio-inositol e 6 g.L. $L^{-1}$ de ágar, sendo o pH ajustado para 5,8, antes da inclusão do ágar. Os meios foram autoclavados a $121^{\circ} \mathrm{C}$ e 1,5 atm por 20 minutos. Após a inoculação, os explantes, foram transferidos para a sala de crescimento com temperatura de $25 \pm 2{ }^{\circ} \mathrm{C}$, luminosidade de $27 \mu$ mols. $\mathrm{m}^{-2} . \mathrm{s}^{-1}$ e fotoperíodo de 16 horas. Aos 30 dias de cultivo, avaliou-se o número médio e comprimento de brotações; e o número médio de gemas e de folhas por explante. Os dados foram submetidos à análise de variância pelo teste $\mathrm{F}$ e as médias dos tratamentos comparadas estatisticamente pelo teste de Duncan e regressão polinomial, por meio do programa estatístico WinStat (Machado \& Conceição, 2002).

\section{RESULTADOS E DISCUSSÃO}

Experimento 1: Multiplicação in vitro de amoreira-preta 'Xavante'

Houve efeito significativo da interação tripla entre o tipo de meio de cultura, de citocinina e a concentração do regulador de crescimento. O número de brotações da cultivar Xavante foi estimulado pelo aumento da concentração de BAP em meio MS. O maior número de brotações por explante foi obtido em meio MS com $15 \mu \mathrm{M}$ de BAP, com o ponto de máxima obtido em 13,3 $\mu \mathrm{M}$ (Figura 1).

Com o aumento das concentrações de BAP e Zeatina, em meio MS, pode-se constatar que houve um aumento no número de brotações até a concentração de $15 \mu \mathrm{M}$, obtendo ponto de máxima em 13,33 $\mu \mathrm{M}$ e 12,6 $\mu \mathrm{M}$, respectivamente, logo, observa-se um decréscimo da variável analisada. Para BAP em meio WPM, observa-se uma tendência linear, aumento da concentração de BAP aumenta o número de brotações. Villa et al. (2005), trabalhando com amoreira-preta 'Ébano' que observou queda no número de brotos com maior concentração de BAP. Esses mesmos autores obtiveram maior número de brotos com a utilização de $150 \%$ de sais no meio MS. 


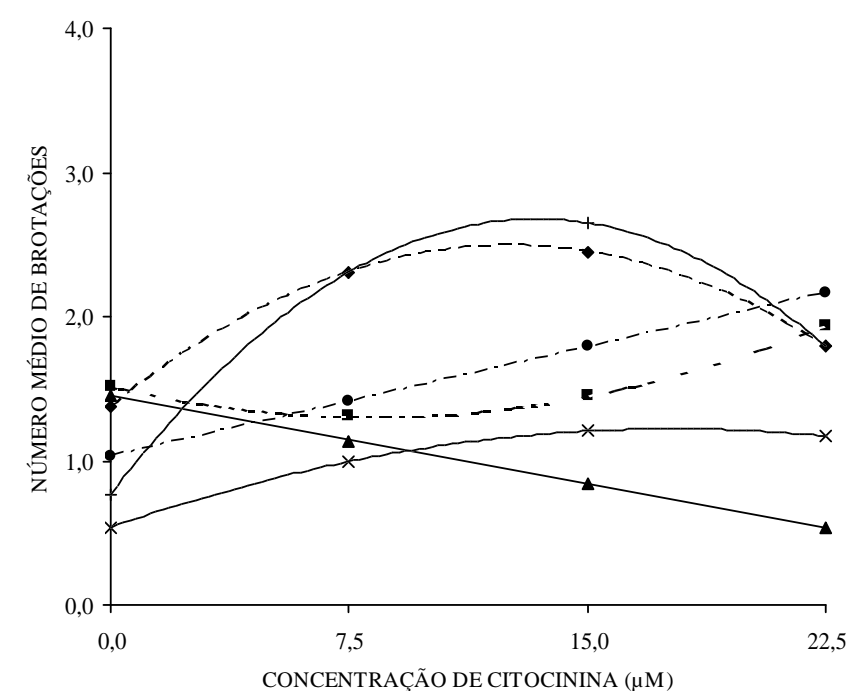

$$
\begin{aligned}
& \text { Zea MS y }=-0,0071 \times 2+0,1787 x+1,37 R^{2}=0,99 \\
& \text { Zea WPM y }=0,0031 x 2-0,0513 x+1,52 R^{2}=1 \\
& \text { \ } 2 \text { iP MS y }=-0,0408 x+1,449 R^{2}=0,95 \\
& \times 2 \text { iP WPM y }=-0,0022 x 2+0,0771 x+0,539 R^{2}=0,92 \\
& + \text { BAP MS y }=-0,0107 x 2+0,2853 x+0,77 R^{2}=0,99 \\
& \text { - BAP WPM y }=0,0507 x+1,03 R^{2}=0,84
\end{aligned}
$$

Figura 1 - Número médio de brotações de amoreira-preta 'Xavante' em função do tipo de meio de cultura, tipo e concentração de citocinina. Pelotas, RS, 2007.

Em trabalho com macieira, Yui (1990), observou melhores resultados com a aplicação de $5,0 \mathrm{mg} \mathrm{L}^{-1}(22,2$ $\mu \mathrm{M})$ de BAP, comprovando que esse regulador de crescimento deve ser incorporado ao meio de cultura para estimular a taxa de multiplicação dos brotos.

Villa et al. (2006), com a utilização de $1,0 \mathrm{mg} \mathrm{L}^{-1}(4,4$ $\mu \mathrm{M})$ de BAP associado a $100 \%$ de meio WPM, obtiveram maior número médio de brotos/planta em amoreira-preta 'Brazos'. Porém, esses mesmos autores trabalhando com a cultivar Ébano de amoreira-preta obtiveram maior número de brotos com a utilização de $150 \%$ de sais do meio MS.

O número de folhas da cultivar Xavante de amoreirapreta foi estimulado pelo aumento da concentração de BAP e Zeatina com meio MS, observando uma interação tripla entre o tipo de meio de cultivo, tipo de citocinina e a concentração do regulador de crescimento (Figura 2).

Com o aumento das concentrações de BAP com meio MS, pode-se constatar que houve aumento no número de folhas até a concentração $15 \mu \mathrm{M}$, com ponto de máxima obtido em $13 \mu \mathrm{M}$, logo, observa-se um decréscimo para a variável. Resultados semelhantes foram obtidos por Villa et al. (2005), trabalhando com amora-preta 'Ébano', que observou redução no número de folhas com o aumento da concentração de BAP. Oliveira (1994), trabalhando com crisântemo, também observou redução no número de folhas com o aumento das concentrações de BAP. Isso pode ser atribuído ao fato de o regulador de crescimento BAP estimular a formação de maior número de brotos, porém, de tamanho reduzido, apresentando menor número de segmentos nodais e, por conseguinte, folhas.
Para a variável comprimento médio das brotações, observa-se uma interação tripla entre o tipo de meio de cultura, tipo de citocinina e sua concentração. Maior comprimento foi observado em meio MS, sem adição do regulador de crescimento. Com adição de $2 \mathrm{iP}$ com meio MS, o comportamento foi linear descendente, indicando que, com a adição da citocinina $2 \mathrm{iP}$, há uma queda no comprimento das brotações. Já, com meio WPM, observase um aumento do comprimento das brotações até a concentração de 15,5 $\mu \mathrm{M}$ de 2iP (Figura 3).

Villa et al. (2006), trabalhando com a amoreira-preta 'Ébano', obtiveram maior comprimento das brotações $(2,83$ $\mathrm{cm})$ em meio MS 50\%, com 0,5 mg L-1 $(2,2 \mu \mathrm{M})$ de BAP e na ausência dessa citocinina no meio MS $150 \%$ de sais, houve um comprimento de brotação de, $3,79 \mathrm{~cm}$.

Pasqual et al. (1991) observaram que brotos mais alongados da cultivar Ébano de amoreira-preta são obtidos com 1,0 mg L-1 de BAP, 0,001 mg L $\mathrm{mg}^{-1}$ de ANA (ácido naftaleno acético) e que a adição de $\mathrm{AG}_{3}$ (ácido giberélico) ao meio com $1,0 \mathrm{mg} \mathrm{L}^{-1}$ de BAP e $0,001 \mathrm{mg} \mathrm{L}^{-1}$ de ANA resulta em um significativo aumento de número de broto por gema.

Grattapaglia \& Machado (1998) indicaram que a maior eficiência do BAP em relação às citocininas Cinetina e $2 \mathrm{iP}$ pode estar na capacidade dos tecidos vegetais metabolizarem os reguladores de crescimento naturais mais rapidamente do que reguladores de crescimento sintéticos. Segundo os autores, isso pode variar em função da espécie de planta utilizada. George (1993) constatou em Gerbera que as citocininas Zeatina e $2 \mathrm{iP}$ podem apresentar 
inatividade por serem rapidamente degradadas pela ação da enzima natural citocinina oxidase, pela quebra da dupla ligação da cadeia lateral da molécula. Esse fato poderia explicar os baixos índices de multiplicação alcançados nos tratamentos com estas citocininas.

Welander (1995), em trabalho de micropropagação de amoreira, também concluiu que o BAP foi superior a outras citocininas (2iP, Zeatina e Cinetina) testadas na multiplicação. Krikorian (1991) comenta que o BAP tem sido mais utilizado atualmente que as citocininas Cinetina e Zeatina por ser um composto mais ativo que se encontra facilmente e, com custo razoável. O autor completa, ainda, que as adenilcitocininas (Zeatina e Cinetina, por exemplo) somente apresentaram atividade na presença de uma auxina, como o AIA, por exemplo, em pesquisas com cenoura e medula de tabaco.

Experimento 2: Multiplicação in vitro de Framboeseira 'Batum'

Houve efeito significativo da interação entre tipo de meio de cultura e concentração da citocinina para as variáveis número médio de gemas, número médio de folhas e número médio de brotações. Não houve interação desses fatores para a variável comprimento médio das brotações. Com o aumento das concentrações de citocinina pode-se constatar que houve aumento para todas as variáveis citadas anteriormente. Maior média para as variáveis foi observado em meio WPM com 15 $\mu \mathrm{M}$, obtendo ponto de máxima em $13 \mu \mathrm{M}$ (Figuras 4, 5 e 6).

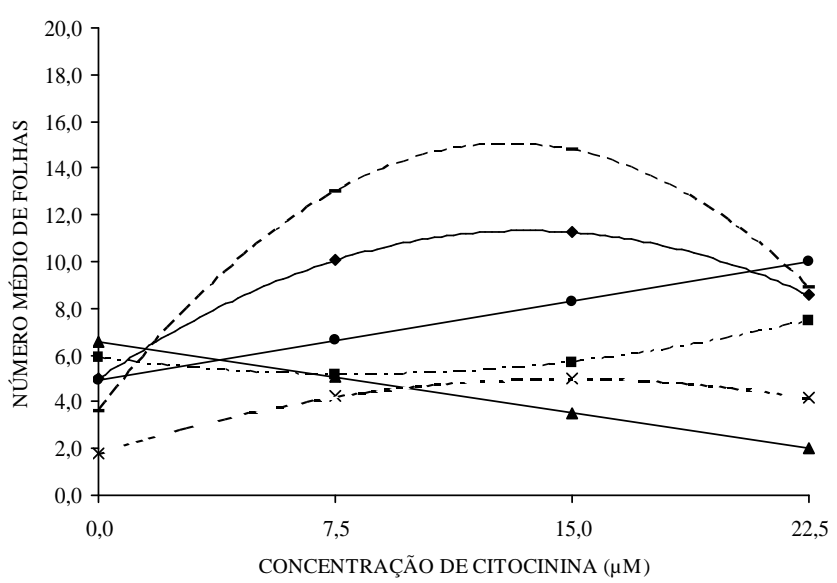

$$
\begin{aligned}
& \text { Zea MS y }=-0,0344 x 2+0,9346 x+4,98 R^{2}=0,99 \\
& \text { Zea WPM y }=0,0111 x 2-0,1793 x+5,88 R^{2}=1 \\
& \text { \ } 2 \text { iP MS y }=-0,2044 x+6,602 R^{2}=0,87 \\
& \times 2 \text { iP WPM y }=-0,0147 x 2+0,4353 x+1,79 R^{2}=0,93 \\
& \text { - BAP MS y }=-0,068 x 2+1,766 x+3,57 R^{2}=0,99 \\
& \text { - BAP WPM y }=0,224 x+4,93 R^{2}=0,87
\end{aligned}
$$

Figura 2 - Número médio de folhas de amoreira-preta 'Xavante' em função do tipo de meio de cultura, tipo e concentração de citocinina. Pelotas, RS, 2007.

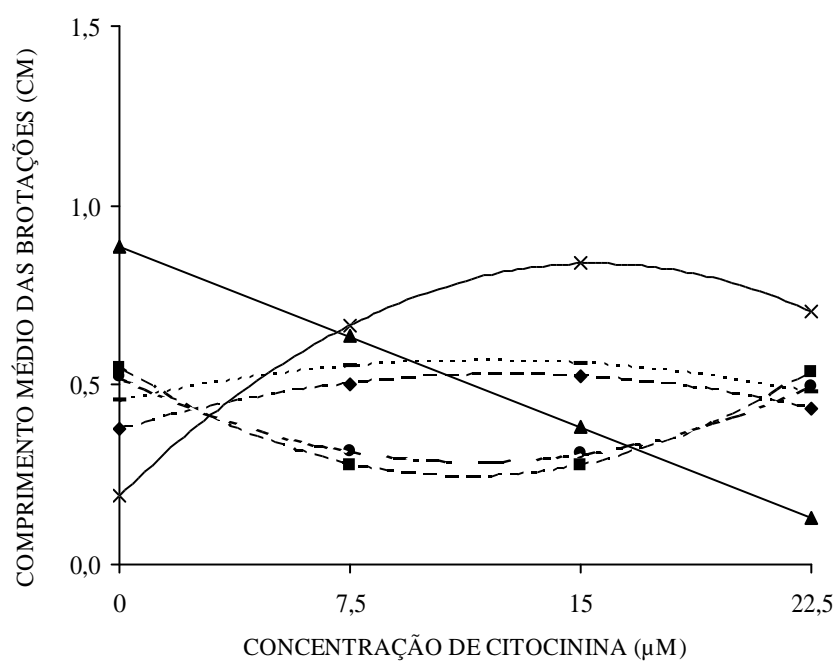

$$
\begin{aligned}
& \text { Zea MS y }=-0,001 x 2+0,0243 x+0,38 R^{2}=0,84 \\
& \text { Zea WPM y }=0,0024 x 2-0,0538 x+0,5491 R^{2}=0,98 \\
& \Delta 2 \text { PP MS y }=-0,0335 x+0,887 R^{2}=0,90 \\
& \times 2 \text { PP WPM y }=-0,0027 x 2+0,084 x+0,193 R^{2}=0,86 \\
& \text { - BAP MS y }=-0,0008 x 2+0,02 x+0,45 R^{2}=0,61 \\
& \text { - BAP WPM y }=0,0017 x 2-0,0404 x+0,522 R^{2}=0,60
\end{aligned}
$$

Figura 3 - Comprimento médio das brotações de amoreira-preta 'Xavante' em função do tipo de meio de cultura, tipo e concentração de citocinina. Pelotas, RS, 2007. 


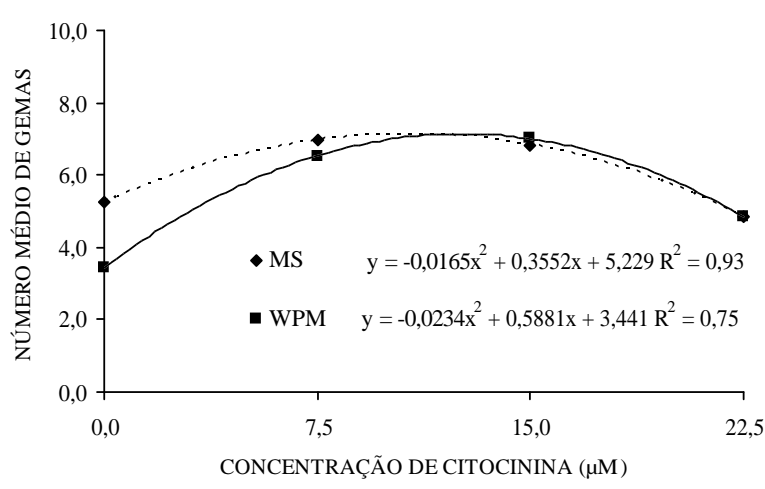

Figura 4 - Número médio de gemas de framboeseira 'Batum' em função do tipo de meio de cultura e da concentração da citocinina no meio de cultura. Pelotas, RS, 2007.

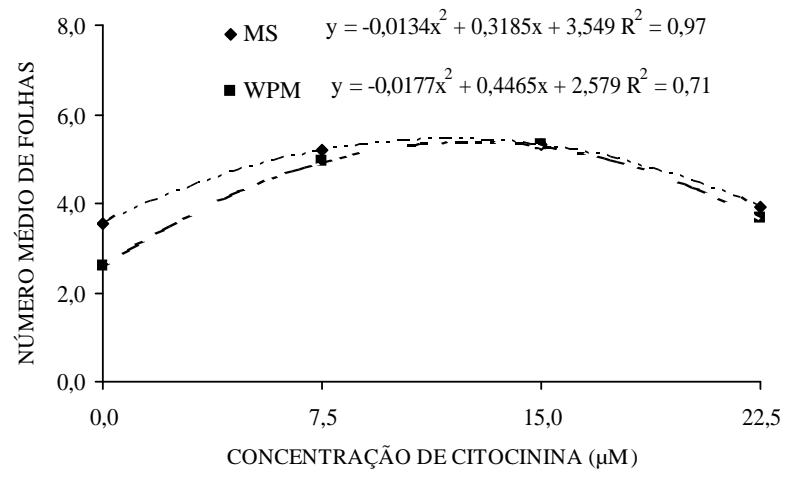

Figura 5 - Número médio de folhas de framboeseira 'Batum' em função do tipo de meio de cultura e da concentração da citocinina no meio de cultura. Pelotas, RS, 2007.

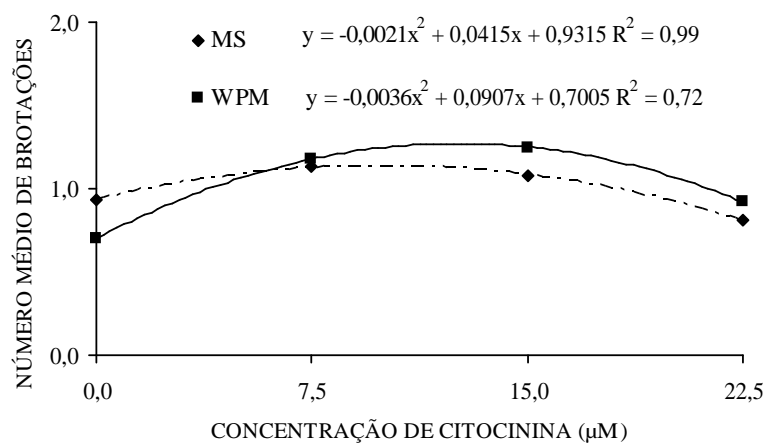

Figura 6 - Número médio de brotações de framboeseira 'Batum' em função do tipo de meio de cultura e da concentração da citocinina no meio de cultura. Pelotas, RS, 2007.
Villa et al. (2006), obtiveram maior número de brotações e comprimento das mesmas em meio WPM adicionado de $0,1 \mathrm{mg} \mathrm{L}^{-1}(0,444 \mu \mathrm{M})$ de BAP. A utilização de WPM implicaria em maior custo em semelhante volume de solução, não justificando, portanto, a utilização deste meio. Em meio MS, observa-se maiores médias para as variáveis número de gemas, brotações e folhas, com o acréscimo de $15 \mu \mathrm{M}$, obtendo ponto de máxima em $11 \mu \mathrm{M}$, $10 \mu \mathrm{M}$ e $12 \mu \mathrm{M}$ de citocinina, respectivamente.

Dzazio et al. (2002), trabalhando com porta-enxerto de videira ' 420 - A', testaram diferentes meios de cultura para o alongamento e multiplicação in vitro e observaram que o meio MS com concentração normal de sais apresentou resultados inferiores para o comprimento de brotação principal, número de folhas do explante e porcentagem de gemas axilares brotados, sendo o melhor meio de cultura, o MS/2 isento de reguladores de crescimento. Silveira et al. (2001), verificaram que o melhor meio de cultivo para multiplicação in vitro de porta-enxertos do gênero Prunus:

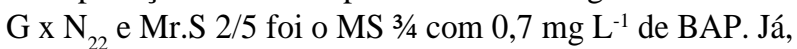
para o porta-enxerto 'Marianna' o melhor meio foi MS com $0,7 \mathrm{mg} \mathrm{L}^{-1}$ de BAP e para o porta-enxerto 'Mirabolano' foi o MS $3 / 4$ com $0,5 \mathrm{mg} \mathrm{L}^{-1}$ de BAP.

O número médio de gemas e de folhas da cultivar Batum foi estimulado pelo aumento da concentração de BAP, observando a interação entre o tipo de citocinina e sua concentração. Para a variável número de brotações, não houve interação entre estes dois fatores (Figuras 7 e 8).

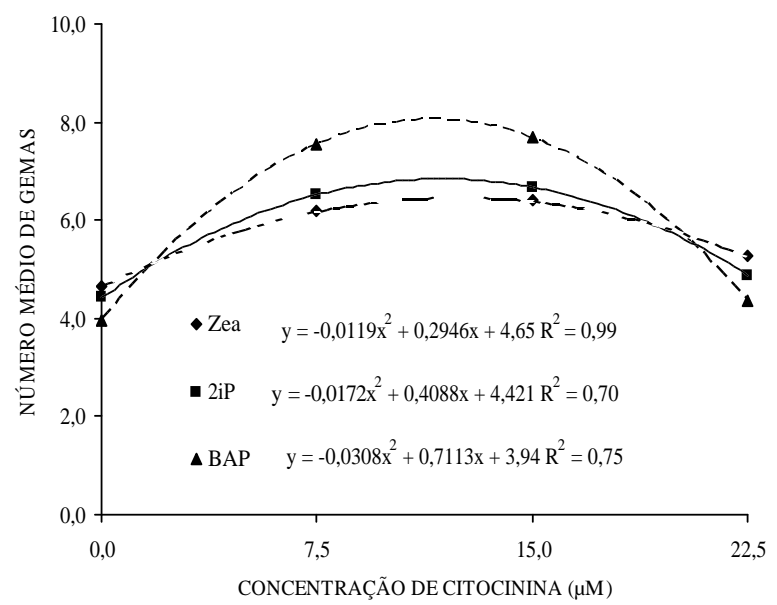

Figura 7 - Número médio de gemas de framboeseira 'Batum' em função do tipo e da concentração da citocinina no meio de cultura. Pelotas, RS, 2007. 


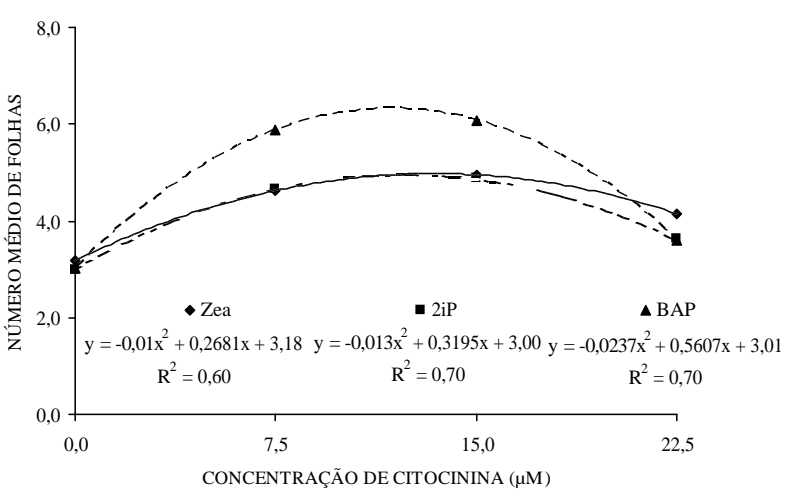

Figura 8 - Número médio de folhas de framboeseira 'Batum' em função do tipo e da concentração da citocinina no meio de cultura. Pelotas, RS, 2007.

Maior número de gemas e de folhas foi observado com as concentrações $15 \mu \mathrm{M}$, com ponto de máxima em $11,5 \mu \mathrm{M}$ e 11,8 $\mu \mathrm{M}$ de BAP, o comportamento foi quadrático, indicando que houve aumento até o ponto de máxima, depois mostrou certo decréscimo. Resultado esta de acordo com Rogalski et al. (1999) e Rogalski \& Leontiev-Orlov (1999), que na multiplicação in vitro de ameixeira observaram uma diminuição do número de brotos com o aumento da concentração de BAP, e obtiveram melhor resultado na concentração de $0,1 \mathrm{mg} \mathrm{L}^{-1}$ de BAP.

Entretanto, esses resultados diferem de Erig et al. (2002) os quais obtiveram máxima indução de multiplicação de brotações, também aos 28 dias de cultivo, em meio MS e na presença de BAP com concentrações de 2, 4 e $6 \mu \mathrm{M}$.

Leontiev-orlov et al. (2000) testaram deferentes concentrações de BAP na multiplicação in vitro de Prunus sp. e observaram maior multiplicação de brotos quando utilizado a concentração $0,75 \mathrm{mg}$. $\mathrm{L}^{-1}(3,33 \mu \mathrm{M})$ de BAP.

Uma rápida proliferação de gemas axilares de amoreirapreta, a cultivares Thornless Boysenberry e Thornless Yongberry, foi obtida em meio MS acrescido de $2,0 \mathrm{mg} \mathrm{L}^{-1}$ $(8,88 \mu \mathrm{M})$ de BAP e $0,1 \mathrm{mg} \mathrm{L}^{-1}$ de ANA (Skirvin et al., 1981).

Villa et al. (2005) obtiveram maior número de folhas em meio MS e $1,0 \mathrm{mg} \mathrm{L}^{-1}$ de BAP $(4,44 \mu \mathrm{M})$ para amoreirapreta 'Ébano', diferindo dos resultados encontrados nesse trabalho onde se obteve maiores número de folhas com a adição de 11,8 $\mu \mathrm{M}$ de BAP.

Porém, observa-se, na tabela 1, para a variável comprimento das brotações, um efeito isolado do tipo de citocinina. Os resultados referentes à zeatina são estatisticamente superiores às demais citocininas estudadas.

Experimento 3: Multiplicação in vitro de Framboeseira 'Heritage'.
Houve efeito significativo da interação entre o tipo de meio de cultura e concentração da citocinina para as variáveis número médio de gemas, número médios de brotações, número médio de folhas e comprimento médio das brotações (Figura 9). Em meio MS, à medida que aumenta a concentração de citocinina observa-se aumento do número de gemas, brotações, comprimento das brotações e no número médio de folhas.

O resultado referente à variável número de gemas, brotações e de folhas, de framboeseira 'Heritage', em meio MS, foi representado por uma tendência linear ascendente. Com o aumento na concentração de citocinina, houve um aumento das médias das variáveis citadas. Leontiev-Orlov et al. (2000), trabalhando com multiplicação de prunáceas, obtiveram melhores resultados, utilizando concentrações entre 0,25 a $0,75 \mathrm{mg} \mathrm{L}^{-1}(1,11$ a $3,33 \mu \mathrm{M})$ de BAP.

Observa-se, na tabela 2, efeito isolado do fator tipo de citocinina para as variáveis número médio de gemas, de folhas e comprimento médio das brotações.

Maiores médias foram alcançadas com a utilização de $2 \mathrm{iP}$ e BAP, para número médio de folhas, diferindo estatisticamente da citocinina Zeatina, para número médio de gemas observam-se maiores médias com a utilização de 2 iP e BAP, já para o comprimento das brotações observa-se maiores médias com $2 \mathrm{iP}$ não diferindo da citocinina zeatina. A utilização de Zeatina ou $2 \mathrm{iP}$ implicaria em maior custo em semelhante volume de solução, com relação ao uso de BAP, não justificando, portanto, a utilização destas no meio de cultivo.

Resultado semelhante foi encontrado por Leontiev-orlov et al. (2000b), onde concluíram que a presença de BAP no meio, ocasiona menor comprimento médio dos brotos. Dustan et al. (1992) afirmam que a adição de BAP ao meio de cultura nem sempre proporciona adequado alongamento das brotações.

Villa et al. (2005), trabalhando com amoreira-preta 'Ébano', obtiveram com o uso de BAP no comprimento das brotações, uma diminuição, de acordo com o aumento da concentração do BAP. Esses resultados concordam com a maioria dos autores, que afirmam que esse regulador de crescimento não é responsável pelo alongamento dos brotos (Earle \& Langhans, 1974; Taiz \& Zeiger, 1991; Paiva et al., 1997a).

Paiva et al. (1997b), trabalhando com Gloxinia, observou também uma redução do tamanho de brotos com o aumento das concentrações de BAP e, alguns autores, têm observado os mesmos resultados negativos desse regulador de crescimento no alongamento das brotações em espécies como crisântemo e morangueiro (Oliveira, 1994; Pasqual et al., 2002). 
Tabela 1 - Comprimento das brotações de framboeseira cv. Batum em função da citocinina utilizada no meio de cultivo. Pelotas, RS, 2007.

\begin{tabular}{cc}
\hline Tipo de citocinina & Comprimento da brotação $(\mathrm{cm}) *$ \\
\hline Zeatina & $0,8 \mathrm{a}$ \\
$2 \mathrm{iP}$ & $0,64 \mathrm{~b}$ \\
BAP & $0,55 \mathrm{~b}$ \\
CV $(\%)$ & 40,72 \\
\hline
\end{tabular}

* Médias seguidas da mesma letra minúscula não diferem entre si pelo teste de Duncan ao nível de 5\% de probabilidade.

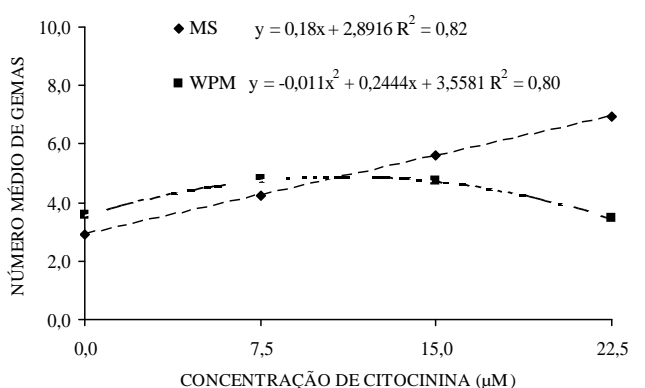

A

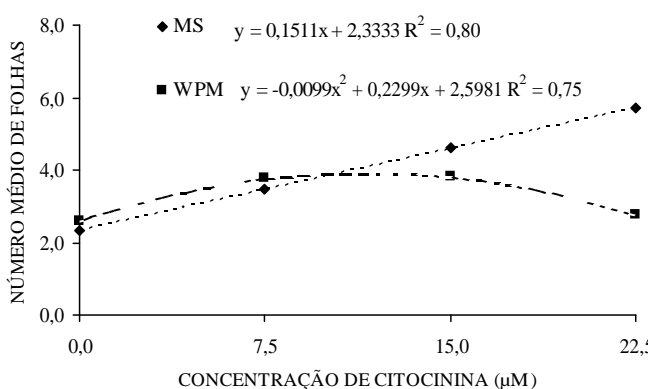

$\mathrm{C}$

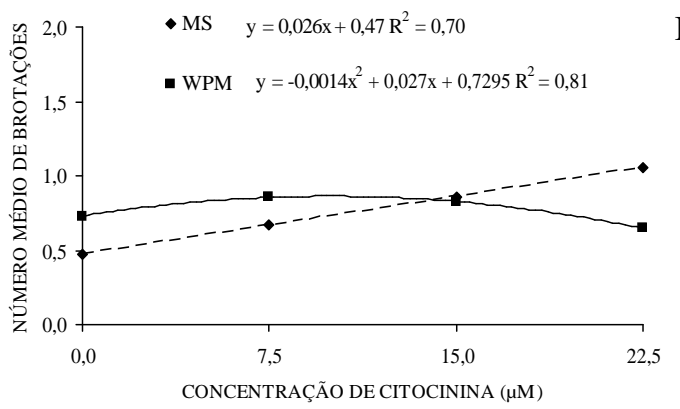

$\mathrm{B}$

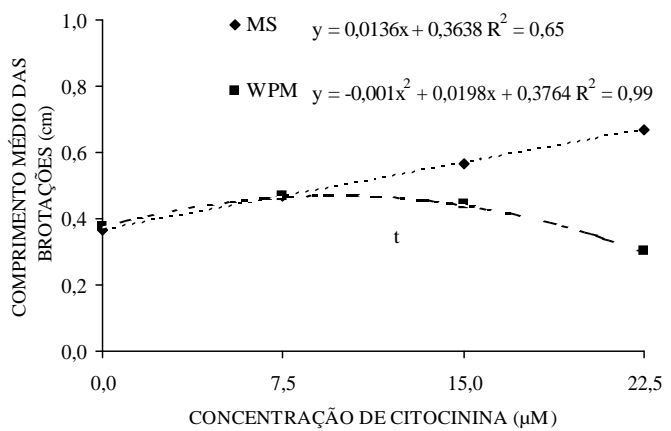

$\mathrm{D}$

CONCENTRAÇ̃̃O DE CITOCININA ( $\mu$ M)

Figura 9 - Número médio de gemas (A), número médio de brotações (B), número médio de folhas (C) e comprimento médio das brotações (D) de framboeseira 'Heritage' em função do tipo de meio e da concentração da citocinina no meio de cultura. Pelotas, RS, 2007.

Tabela 2 - Número médio de gemas, número médio de folhas e comprimento médio das brotações de framboeseira 'Heritage' em função do tipo de citocinina. Pelotas, RS, 2007.

\begin{tabular}{cccc}
\hline Tipo de Citocinina & Número médio de gemas & Número médio de folhas & $\begin{array}{c}\text { Comprimento médio das } \\
\text { brotações }(\mathrm{cm})\end{array}$ \\
\hline 2iP & $5,29 \mathrm{a}$ & $4,14 \mathrm{a}$ & $0,56 \mathrm{a}$ \\
BAP & $4,71 \mathrm{ab}$ & $3,93 \mathrm{a}$ & $0,35 \mathrm{~b}$ \\
Zeatina & $3,59 \mathrm{~b}$ & $2,83 \mathrm{~b}$ & $0,46 \mathrm{ab}$ \\
CV $(\%)$ & 26,86 & 26,91 & 48,89 \\
\hline
\end{tabular}

* Médias seguidas da mesma letra minúscula nas colunas não diferem entre si pelo teste de Duncan ao nível de 5\%. 


\section{CONCLUSÕES}

Conclui-se que o meio MS adicionado de $13 \mu \mathrm{M}$ de BAP promove a multiplicação in vitro de amoreira-preta 'Xavante'.

Maior número de folhas, gemas e brotações de framboesa 'Batum' e 'Heritage' foram obtidas em meio MS acrescido de $12 \mu \mathrm{M}$ de BAP.

Maior comprimento de brotações para amoreirapreta o cultivo foi obtido em meio MS na ausência de regulador; para framboeseira 'Batum' foi obtido com Zeatina; e de 'Heritage' foi $2 \mathrm{iP}$, independentemente das concentrações utilizadas.

\section{AGRADECIMENTOS}

Este trabalho foi desenvolvido com o apoio do Ministério da Ciência e Tecnologia (MCT); Conselho Nacional de Desenvolvimento Científico e Tecnológico $(\mathrm{CNPq})$; Fundação de Amparo à Pesquisa do Estado do Rio Grande do Sul (FAPERGS).

\section{REFERÊNCIAS BIBLIOGRÁFICAS}

ANTUNES, L.E.C. Aspectos fenológicos, propagação e conservação pós-colheita de frutas de amoreira-preta (Rubus spp) no sul de Minas Gerais. 1999. 129p. Tese (Doutorado em Fitotecnia)-Universidade Federal de Lavras, Lavras, 1999.

DUSTAN, D.I.; LASHTA, D.P.; KIKCIO, S.I. Factors affecting reccurrent shoot multiplication in vitro cultures of 17 to 20 years-old douglas fir trees. In Vitro Cell Development Biology, Columbia, v.28, p.33-38, 1992.

DZAZIO, P.M.; BIASI, L.A.; ZANETTE, F.

Micropropagação do porta-enxerto de videira '420-A'. Revista Brasileira de Fruticultura, Jaboticabal, v.24, n.3, p.759-764, 2002.

EARLE, E.D.; LANGHANS, R.W. Propagation of Crysanthemum in vitro: II., production, growth and flowering of plantlets from tissues culture. Jounal of American Society for Horticultural Science, Alexandria, v.99, n.4, p.352-358, 1974.

ERIG, A.C.; ROSSI, A. de; FORTES, G.R.L. de. 6benzilaminopurina e ácido indolbutírico na multiplicação in vitro da amoreira - preta (Rubus idaeus L.), cv. Tupy. Ciência Rural, Santa Maria, v.32, n.5, 2002.
GEORGE, E.F. Plant propagation by tissue culture. 2.ed. Edington: Exegetics, 1993. 2v.

GRATTAPAGLIA, D; MACHADO, M.A.

Micropropagação. In: TORRES, A.C.; CALDAS, L.S.; BUSO, J.A. Cultura de tecidos e transformação genética de plantas. Brasília: Embrapa-SPI/Embrapa-CNPH, 1998. v.1, p.183-260.

HU, C.Y.; WANG, P.J. Meristem, shoot tip and bud culture. In: EVANS, D.A.; SHARP, W.R. Handbook of plant cell cultures. New York: Macmillan, 1983. v.1, p.177-227.

JENNINGS, D.L.; McNICOL, R.J. Rubus breeding: recent progress and problems. Plant Breeding Abstracts, Berlin, v.61, p.753-758, 1991.

KRIKORIAN, A.D. Medios de cultivo: generalidades, composición y preparación. In: ROCA, W.R.; MROGINSKI, L.A. Cultivo de tejidos en la agricultura: fundamentos y aplicaciones. Cali: Centro Internacional de Agricultura Tropical, 1991. p.41-78.

LEONTIEV-ORLOV, O. Propagation of plant of Rubus generation by the method of cutting. [S.1.]: Problems of Modern Horticulture, 1989. 37p.

LEONTIEV-ORLOV, O.; ROGALSKI, M.; MOSSI, A.J.; CANSIAN, R.L. 6- Benzilaminopurina (BAP) na multiplicação in vitro de prunáceas (Prunus sp.) Revista Brasileira de Agrociência, v.6 n.1, p.42-46, jan./abr/ 2000.

LLOYD, G.; McCOWN, B. Commercially-feasible micropropagation of mountain laurel, Kalmia latifolia, by use of shoot-tip culture. Combined Proceedings International Plant Propagators Society, v.30, p.421-427, 1980.

MACHADO, A.; CONCEIÇÃO, A.R. Programa estatístico WinStat - Sistema de Análise Estatístico para Windows. Versão 2.0. Pelotas, 2002.

MURASHIGE, T.; SKOOG, F. A revised medium for rapid growth and biossay with tobacco tissue cultures. Physiologia Plantarum, Cepenhagen, v.15, p.473-497, 1962. 
OLIVEIRA, P.D. Propagação in vitro de crisântemo (Dendranthema grandiflora Tzlev.) cv. Orange Reagen. 1994. 116f. Dissertação (Mestrado em Fitotecnia)-Escola Superior de Agricultura de Lavras, Lavras, 1994.

PAIVA, P.D.O. de; JOSÉ, S.C.B.R.; PASQUAL, M.; PAIVA, R. Efeito do ácido naftaleno acético e GA3 na micropropagação de violeta. Revista Ceres, Viçosa, v.44, n.254, p.392-398, 1997a.

PAIVA, P.D.O. de; MAYER, M.B.D.; CAMPOS, R.J.C.; RODRIGUES, V.A.; PASQUAL, M. Propagação in vitro de gloxínia. Revista Brasileira de Horticultura Ornamental, Campinas, v.3, n.2, p.29-41, 1997 b.

PASQUAL, M.; ALVES, G.P.; DUTRA, L.F.; FINOTTI, D.R.; CHAGAS, E.A. Cultivo in vitro de embriões imaturos de tangerina 'Poncã': concentrações do meio MS e da sacarose. Revista Ceres, Viçosa, v.49, n.282, p.181-189, 2002.

PASQUAL, M.; PEIXOTO, P.H.P.; SANTOS, J.C. do; PINTO, J.E.B.P. Propagação "in vitro" da amora-preta (Rubus sp.)cv. Ébano: uso de reguladores de crescimento. Ciência e Prática, Lavras, v.15, n.3, p.282286, 1991.

RASEIRA, M. do C.B.; SANTOS, A.M. dos; MADAIL, J.C.M. Amora-preta: cultivos e utilização. Pelotas: Embrapa-CNPFT, 1984. 20p. (Circular técnica, 11).

ROGALSKI, M.; LEONTIEV-ORLOV, O. Estudo da micropropagação e morfogênese em ameixeira e pessegueiro. Erechim: Universidade Regional Integrada do Alto-Uruguai e das Missões, 1999. 151p. Relatório técnico-científico PIBIC/CNPq.

ROGALSKI, M.; LEONTIEV-ORLOV, O.; MOSSI, J.A.; CANSIAN, R.L. Efeito de diferentes concentrações de benziladenina (BA) e macroíons na multiplicação in vitro de ameixeira (Prunus domestica L. - var.

Kantimirovskaja) In: CONGRESSO NACIONAL DE GENÉTICA, 45., 1999, Gramado. Anais... Gramado: SBG, 1999. p.714a.
SANTOS, A.M. dos; RASEIRA, M. do C.B. Lançamento de cultivares de amoreira-preta. Pelotas: EmbrapaCNPFT, 1988. Não paginado. (Informativo, 23).

SCHUCH, M.W.; ERIG, A.C. Micropropagação de plantas frutíferas. In: ___ Propagação de plantas frutíferas. Pelotas: UFPel, 2005.

SILVEIRA, C.A.P.; FACHINELLO, J.C.; FORTES, G.R.L. de; CITADIN, I.; RODRIGUES, A.C.; QUEZADA, A.C.; SILVA, J.B. Multiplicação in vitro de porta-enxerto do gênero Prunus sob diferentes concentrações de BAP em dois meios de cultura. Revista Brasileira de Fruticultura, Jaboticabal, v.23, n.3, p.488-492, 2001.

SKIRVIN, R.M.; CHU, M.C.; GOMEZ, E. In vitro propagation of Thornless Treiling Blackberies. HortScience, Alexandria, v.16, n.3, p.310-312, 1981.

SRISKANDARAJAH, S.; MULLINS, M.G.; NAIR, Y. Induction of adventitions rooting in vitro in difficult to propagate cultivars of apple. Plant Science Letters, Limerick, v.24, p.1-9, 1982.

TAIZ, L.; ZEIGER, E. Plant physiology. Redwood City: [s.n.], 1991. 424p.

VILLA, F.; ARAÚJO, A.G. de; PIO, L.A.S.; PASQUAL, M. Multiplicação in vitro da amoreira-preta 'Ébano' em diferentes concentrações de meio MS e BAP. Ciência Agrotecnologia, Lavras, v.29, n.3, p.582-589, 2005.

VILLA, F.; FRÁGUAS, C.B.; DUTRA, L.F.; PIO, L.A.S.; PASQUAL, M. Multiplicação in vitro de amoreira-preta cultivar Brazos. Ciência e Agrotecnologia, Lavras, v.30, n.2, p.266-270, 2006.

WELANDER, M. In vitro culture of raspberry (Rubus idaeus) for mass propagation. Journal of Horticultural Science, Ashford, v.60, n.4, p.493-499, 1985.

YUI, E. Multiplicação in vitro de porta enxerto de macieira (Malus x domestica Borck). 1990. 69f. Dissertação (Mestrado)-Escola Superior de Agricultura de Lavras, Lavras, 1990. 